\title{
Patient and Physician Perceptions of the Impact of Electronic Health Records on the Patient-Physician Relationship
}

\author{
Margaret Eberts ${ }^{1,2}$ Daniel Capurro ${ }^{3,4}$ \\ ${ }^{1}$ Sidney Kimmel Medical College, Thomas Jefferson University, \\ Philadelphia, Pennsylvania, United States \\ ${ }^{2}$ Department of Computer Science, Swarthmore College, \\ Swarthmore, Pennsylvania, United States \\ 3 Pontificia Universidad Catolica de Chile Facultad de Medicina, \\ Santiago, Chile \\ ${ }^{4}$ School of Computing and Information Systems, Melbourne School of \\ Engineering, University of Melbourne Melbourne, Victoria, Australia
}

\author{
Address for correspondence Margaret Eberts, Sidney Kimmel Medical \\ College, Thomas Jefferson University, 1025 Walnut St \#100, \\ Philadelphia, PA 19107, United States \\ (e-mail: margaretc.eberts@gmail.com).
}

Appl Clin Inform 2019;10:729-734.

\begin{abstract}
Keywords

- electronic health records and systems

- patient records

- specific types

Objectives Limited studies have been performed in South America to assess patient and physician perceptions of electronic health record (EHR) usage. We aim to study the perceptions of patients and physicians regarding the impact of EHRs on the patientphysician relationship.

Methods We use a survey instrument to assess the physician computer experience and opinions regarding EHR impact on various aspects of patient care. An additional survey is used to assess patient opinions related to their medical visit. Surveys are administered in two outpatient clinics in a private, academic health care network.

Results While a majority of physicians believed that EHRs have an overall positive impact on the quality of health care, many physicians had negative perceptions of the impact of EHRs on the patient-physician relationship. A majority of patients felt comfortable with their physician's use of the EHR and felt that their physician was able to maintain good personal contact while using the computer.

Conclusion Although physicians believe EHRs have a generally positive impact on the overall quality of care, the EHR's impact on the patient-physician relationship is still of concern. Patients do not perceive a negative interference from the EHR on the patientphysician relationship.
\end{abstract}

\section{Background and Significance}

The use of electronic health record (EHR) systems in outpatient care settings is growing internationally. However, physicians are often hesitant to adopt EHR systems in their practice, expressing concerns of a possible detrimental impact on the patient-physician relationship as a result of EHR use while the patient is present. ${ }^{1,2}$ Compared with adoption rates of above $90 \%$ for the use of EHR among primary care physician practices in countries such as the Netherlands, Norway, New Zealand, the United Kingdom, and Australia, ${ }^{3}$ adoption of EHR systems has progressed more slowly in South America. According to a 2015 report, between 50 and $75 \%$ of primary care facilities and less than $25 \%$ of secondary and tertiary care facilities in Chile use EHR systems. ${ }^{4}$ Physician resistance as well as the lack of studies on the impact of EHR systems specifically in South American may be contributors to the lower adoption rate in Chile. received

May 25, 2019

accepted after revision

July 26, 2019 (c) 2019 Georg Thieme Verlag KG Stuttgart · New York
DOI https://doi.org/

$10.1055 / \mathrm{s}-0039-1696667$. ISSN 1869-0327. 
Studies have been performed in the United States and other developed countries to assess the outcomes of EHR implementation and patient and physician perceptions of these systems. Physicians often indicate that EHR use may prevent them from focusing on their patients and may impede communication. ${ }^{1,2,5}$ Physicians have reported a negative effect of EHRs on their ability to maintain eye contact with patients and their ability to actively listen to patients. ${ }^{6}$ Additionally, physicians looking at an EHR during the clinical encounter may appear distracted or disinterested, potentially impacting the patient's perceptions of the physician. ${ }^{7}$ Despite these initial negative perceptions of EHR implementation, research reveals improved efficiency in hospitals and outpatient clinics, ${ }^{2}$ clinician acceptance and approval of the EHR systems, ${ }^{2,5,8}$ and overall patient satisfaction ${ }^{1,2,8-14}$ with EHR use.

Review of the literature reveals that very few studies have investigated patient and physician perceptions of, and the impact of, EHR systems in South America. Given that patientphysician communication has a strong cultural component, findings from studies conducted in the United States and other developed countries may not be entirely transferrable to other settings. For this reason, studies focusing on the impact of EHR systems on the patient-physician relationship specifically in South American countries are needed.

\section{Objectives}

Our objectives in this study were to (1) determine the perceptions of physicians regarding EHR use in outpatient clinics, specifically regarding the impact of EHR use on the quality and content of their patient-physician interactions and the rapport established with their patients, and (2) assess patients' satisfaction with their outpatient encounters and their perceptions of EHR use in relation to communication with their physician.

\section{Methods}

Two survey instruments were used in the study. The patient satisfaction survey is a translated version of a previously validated survey to assess patients' attitudes regarding electronic medical record use during outpatient encounters. ${ }^{15}$ The 42-item instrument includes items relating to general patient satisfaction and physician computer use. Items from the 12-Item Short Form instrument to assess general health quality and items to obtain demographic data, including the patient's familiarity with computers, are included in the instrument. The 78-item physician survey is an adaptation of a previously validated instrument to assess physicians' general attitudes toward computer use in medicine ${ }^{15}$ and a validated instrument to assess computer literacy. ${ }^{16}$ Both survey instruments were translated from English to Spanish and then retro-translated to English to ensure the clarity and validity of the translation.

The study was conducted within the U.C. CHRISTUS health care network, a private, academic health care network with 2 hospitals and 10 outpatient clinics in Santiago, Chile. The study was approved by the medical ethics board of the Medical
Faculty of the Pontificia Universidad Catolica. Purposive sampling was used, designed to reach several participants consistent with previous studies. We did not estimate a sample size since we only sought to describe differences in perceptions, not to test specific differences. In total, surveys were administered to 100 adult patients and 100 physicians at two of the network's outpatient clinics over a 6-week period. To avoid clustering by physician, we surveyed unique patient-physician pairs. Patients and physicians were approached by a member of the research team and asked whether they were willing to participate in the study before the survey was distributed; all who consented were given a copy of the survey to complete. Since patients usually attended the clinic for a single medical visit, they were asked to complete the patient survey electronically on a tablet immediately after their visit. Physicians were given a paper copy of the physician survey to complete at the end of their day in the clinic.

\section{Results}

A total of 100 physicians and 100 patients were surveyed from the included clinics. Physician and patient sample demographics are described in - Tables 1 and 2, respectively. Physicians used two different EHR systems in the clinics: an older system, developed in-house where physicians mostly document using free-text and very limited functionality, and a second system, an Office of the National Coordinator for Health Information Technology (ONC HIT)-certified EHR ${ }^{17}$ with more robust functionality and implemented 18 months prior to our study. Of the physicians surveyed, $85 \%$ mainly used the ONC HIT-certified EHR, while the remaining 15\% used the older system (-Tables 1 and 2).

Patients and physicians were questioned regarding their general perceptions of EHR use. Overall, only 3\% of patients felt uncomfortable with their physician using a computer to document their medical visits, while $16 \%$ of physicians felt that the impact of EHRs on the overall quality of the health

Table 1 Physician demographics

\begin{tabular}{|c|c|}
\hline Age & Median: 39, range: $25-68$ \\
\hline Sex & $39 \%$ male, $61 \%$ female \\
\hline Specialties & $\begin{array}{l}63 \% \text { nonsurgical } \\
37 \% \text { surgical }^{\mathrm{b}}\end{array}$ \\
\hline $\begin{array}{l}\text { Total hours of computer } \\
\text { usage per week }\end{array}$ & Median: 25 , range: $2-112$ \\
\hline Computer literacy $^{c}$ & $\begin{array}{l}\text { Median: } 68 \text {, range: } 23-75 \\
\text { Scoring from } 0 \text { to } 75 \\
\text { (fully competent) }\end{array}$ \\
\hline
\end{tabular}

${ }^{a}$ Cardiology, diabetes, endocrinology, family medicine, gastrology, geriatrics, hematology, immunology, infectious disease, nephrology, neurology, nutrition, pediatrics, and rheumatology.

${ }^{\mathrm{b} C o l o r e c t a l}$ surgery, dermatology, general surgery, gynecology, maxillofacial surgery, neurosurgery, oncology, ophthalmology, otolaryngology, and traumatology.

'Computer literacy based on 15 variables relating to software, hardware, networks, and information security knowledge. Each variable is scored on a scale of 1 (not competent) to 5 (fully competent), resulting in a highest score of 75 . 
Table 2 Patient demographics

\begin{tabular}{|l|l|}
\hline Age & Median: 41, range: 18-87 \\
\hline Sex & $30 \%$ male, 70\% female \\
\hline Visit type & $35 \%$ initial visit, 65\% follow-up \\
\hline Education & $\begin{array}{l}27 \% \text { completed high school graduate or less } \\
32 \% \text { completed a technical career } \\
\text { or part of university } \\
22 \% \text { graduated from university } \\
19 \% \text { postgraduate degree }\end{array}$ \\
\hline Computer & $\begin{array}{l}25 \% \text { basic or very basic computer users } \\
\text { experience neither basic nor advanced } \\
\text { computer users } \\
45 \% \text { advanced or very advanced } \\
\text { computer users }\end{array}$ \\
\hline
\end{tabular}

care given to their patients is detrimental. Looking more closely at patients' perceptions, of the patients surveyed, we found that $86 \%$ felt that their information is more secure when stored on the computer compared with the older paper system and $61 \%$ felt that their medical visits were more efficient because their physician uses a computer. In total, $98 \%$ of patients were completely satisfied with the care they received. While patients generally had positive perceptions of EHR usage and the care they received, physician perceptions were more varied. Of the physicians surveyed, $51 \%$ felt that EHRs had a detrimental impact on the time required for documentation, $27 \%$ felt that EHRs had a detrimental impact on patient privacy, and $14 \%$ felt that EHRs had a detrimental impact on patients' satisfaction. These proportions of patients and physicians cannot be compared statistically as they are measured with different instruments. - Table 3 provides a more detailed description of findings.

In addition to the general perceptions of EHR use, patients and physicians were also questioned regarding their opin- ions the impact of EHRs specifically in relation to the patientphysician relationship. Out of all patients surveyed, $88 \%$ felt that their physician is able to maintain good personal contact while using the computer and $90 \%$ agreed that they can easily talk with their physician while (s)he uses the computer. Additionally, only $17 \%$ of patients felt that their physician watches the computer rather than them. However, $25 \%$ of physicians felt that EHRs had a detrimental impact on the overall quality and content of their patient-physician interactions. More so, 37\% of physicians felt that the EHRs had a detrimental impact on the rapport established between the physician and patient. - Table 4 provides further detail on the patient and physician perceptions of EHR impact on the patient-physician relationship.

Proportions of physicians who believe that the EHR has a beneficial impact on their patient-physician interactions were compared over groups of physicians divided based on various attributes using chi-squared tests. Hours of computer usage per week $\left(X^{2}=2.02, p=0.3642\right)$, computer literacy $\left(X^{2}=0.0324, p=0.8571\right)$, number of hours of EHR training $\left(X^{2}=0.4246, p=0.5146\right)$, age $\left(X^{2}=2.5921, p=0.2736\right)$, and specialty (surgical vs. nonsurgical: $X^{2}=2.8744, p=0.09$; primary care vs. specialist: $X^{2}=1.2523, p=0.2631$ ) were found to have no significant association with the physicians' perceptions of EHR impact on the patient-physician relationship.

\section{Discussion}

This study demonstrates that while a majority of physicians believe that EHRs have a positive impact on the overall quality of patient care, many physicians still have concerns about the impact of EHRs on the patient-physician relationship. The studies of Fairley et $\mathrm{al}^{2}$ and El-Kareh et $\mathrm{al}^{5}$ have similarly found that physicians believe EHRs generally have a positive impact on the overall quality of care. With respect to the patient-physician

Table 3 Patient and physician general perceptions of EHRs

\begin{tabular}{|c|c|c|c|}
\hline \multicolumn{4}{|l|}{ Patients } \\
\hline & Agree & Neutral & Disagree \\
\hline $\begin{array}{l}\text { I feel comfortable with my physician using a computer } \\
\text { to document my medical visits }\end{array}$ & $83 \%$ & $14 \%$ & $3 \%$ \\
\hline $\begin{array}{l}\text { I feel that my information is more secure when stored on } \\
\text { the computer compared with a paper system }\end{array}$ & $86 \%$ & $11 \%$ & $3 \%$ \\
\hline $\begin{array}{l}\text { I feel that my medical visits are more efficient because } \\
\text { my physician uses a computer }\end{array}$ & $61 \%$ & $13 \%$ & $26 \%$ \\
\hline I am completely satisfied with the care I received & $98 \%$ & $0 \%$ & $2 \%$ \\
\hline \multicolumn{4}{|l|}{ Physicians } \\
\hline The impact of EHRs on ......... is: & Beneficial & Neutral & Detrimental \\
\hline The overall quality of the health care given to my patients & $61 \%$ & $23 \%$ & $16 \%$ \\
\hline The time required for documentation & $28 \%$ & $21 \%$ & $51 \%$ \\
\hline Patient privacy & $27 \%$ & $46 \%$ & $27 \%$ \\
\hline Clinicians' accountability for the care provided & $68 \%$ & $25 \%$ & $7 \%$ \\
\hline The patients' satisfaction with the quality of care they receive & $39 \%$ & $47 \%$ & $14 \%$ \\
\hline
\end{tabular}

Abbreviation: EHR, electronic health record. 
Table 4 Patient and physician perceptions of EHRs in relation to the patient-physician relationship

\begin{tabular}{|c|c|c|c|}
\hline \multicolumn{4}{|l|}{ Patients } \\
\hline & Agree & Neutral & Disagree \\
\hline I feel I can easily talk with my physician while (s)he uses the computer & $90 \%$ & $4 \%$ & $6 \%$ \\
\hline $\begin{array}{l}\text { I believe my physician is able to maintain good personal contact } \\
\text { while using the computer }\end{array}$ & $88 \%$ & $5 \%$ & $7 \%$ \\
\hline I feel my physician watches the computer rather than me & $17 \%$ & $18 \%$ & $65 \%$ \\
\hline \multicolumn{4}{|l|}{ Physicians } \\
\hline The impact of EHRs on .......... is: & Beneficial & Neutral & Detrimental \\
\hline The overall quality and content of my patient-physician interactions & $42 \%$ & $33 \%$ & $25 \%$ \\
\hline The rapport established during the encounter between the physician and patient & $20 \%$ & $43 \%$ & $37 \%$ \\
\hline
\end{tabular}

Abbreviation: EHR, electronic health record.

relationship, this study reveals the dichotomy between patient and physician perceptions of the interference of EHRs. Similar to previous studies, ${ }^{8-14}$ we found that the majority of patients feel that they are able to maintain good communication and a relationship with their physician in the presence of EHRs. As found in other studies, patient satisfaction remained high with physician EHR usage. However, we found that physicians' perceptions vary more, a dichotomy also noted by Gadd and Penrod $^{1}$ and Sobral et al. ${ }^{6}$ Our findings show that, compared with patients, more physicians perceive a negative impact of EHRs on the patient-physician relationship, though the difference between patient and physician perceptions is not as large as the findings of Gadd and Penrod. ${ }^{1}$

Other studies have documented the association or lack of association between physician perceptions of EHRs and various physician attributes. With respect to physician specialty, Emani et al $^{18}$ found that physician specialty is strongly associated with physicians' beliefs regarding EHR impact. They report that, compared with medical specialists and surgical specialists, primary care physicians are more likely to agree that EHR use will improve quality of care. Similarly, Grinspan et $\mathrm{al}^{19}$ found that medical specialists and surgeons are significantly less likely to adopt EHRs in their practice than are general practitioners. In our study, we found no significant difference of the EHR perceptions between surgical versus nonsurgical specialties and primary care practitioners versus specialists.

In terms of physician age, O'Connell et $\mathrm{al}^{20}$ found no significant correlation between physician age and EHR satisfaction. Similarly, Rathert et $\mathrm{al}^{21}$ found no major differences in physicians' perceptions of EHRs based on age, gender, profession, or organization. Our results corroborate these findings, as we found no significant trend between physician age and their perception of EHRs impact on the patientphysician relationship.

Regarding computer experience and amount of EHR training, Jamoom et $\mathrm{al}^{22}$ found that physicians with more experience with EHRs had more positive perceptions about EHR usage. Likewise, Detmer and Friedman ${ }^{23}$ reported that physicians with prior computer training and greater knowledge of informatics concepts had more favorable attitudes toward the use of computers in health care. In O'Connell et al, ${ }^{20}$ while physician
EHR satisfaction was found to correlate significantly with prior EHR experience, they found no significant correlation between physician EHR satisfaction and prior computer experience. In our study, we find that there is no significant association between the physician's level of computer usage or amount of EHR training and their perceptions of the impact of EHRs on the patient-physician relationship.

Though not a major objective of the study, a significant difference was found in the perceptions of physicians using the newer versus older EHR systems regarding the impact of EHRs on the overall quality and content of patient-physician interactions. Physicians using the newer system were more likely to believe that EHRs have a negative impact on their patientphysician interactions. This finding may suggest that with the additional functionality of the newer EHR system, ease of use decreases and perceived EHR interference increases.

A primary motivation of this study was the lower EHR adoption rates of South America compared with more developed countries. A Pan American Health Organization report on the progress of EHR implementation in Latin America and the Caribbean $^{24}$ discussed several key risks and challenges in EHR adoption in these regions. Among the issues discussed in the report, the authors mentioned concerns regarding the interference of EHR during the clinical consultation. Our research addresses this concern, hoping to better understand the effect of the EHR on the South American patient-physician relationship. Our findings suggest that, both when EHRs are designed and when clinical processes are redefined to accommodate them, special attention needs to be paid to the clinician's user experience since that component of the physician-patient relationship seems to be the most affected. On the other hand, these findings help remove some of the clinician's anxieties when adopting a new EHR, emphasizing that their experience continues to be good despite a new device in the room. Noting that these findings are constant across studies and geographies underlines their robustness.

A potential limitation of our study is the small sample size of physicians and patients surveyed. Similarly, patients and physicians were not randomly selected to participate in the study. Rather, patients and physicians were approached in the clinic and asked if they were willing to participate until we reached the predefined sample size. Finally, the survey did not explore 
the reasons behind physician's or patient's perceptions that might explain out findings. In future studies, we plan to include qualitative methods to better understand concerns regarding the impact of EHRs on the patient-physician relationship which could further our understanding of physicians' perceptions.

\section{Conclusion}

We have found that although a majority of physicians believe the EHRs have a positive impact on overall quality of patient care, many physicians have concerns with the potential impact of EHRs on the patient-physician relationship. Patients do not share these concerns regarding the impact of EHRs. Additionally, we have found that physician perceptions of EHRs do not correlate with physician age, specialty, or computer experience. More robust studies are needed to further understand the way in which the use of EHRs interferes with patient-physician communication and relationships.

\section{Clinical Relevance Statement}

Given that both physicians and patients had positive perceptions regarding the impact of EHRs on overall quality of care, the further implementation of EHRs in Chile is promising. However, physicians' concerns regarding the impact of EHRs on the patient-physician relationship should be further addressed.

\section{Multiple Choice Questions}

1. Many studies have been performed in the United States and other developed countries to assess the outcomes of EHR implementations. Major findings of these studies include all of the following except:

a. Improved efficiency in hospital and outpatient clinics with EHR implementation.

b. Clinical acceptance and approval of the EHR systems after implementation.

c. Decreased overall patient satisfaction after EHR implementation.

d. A dichotomy between the perceptions of patients and physicians regarding EHR impact.

Correct Answer: The correct answer is option c. Despite the initial negative perceptions of physicians regarding EHR implementation, many studies have shown that EHR implementation leads to improved efficiency, ${ }^{2}$ clinician acceptance of the EHR systems, ${ }^{2,5,8}$ and overall patient satisfaction. ${ }^{1,2,8-14}$ However, several studies have found that clinicians are not fully satisfied with EHR systems. Some studies have documented a dichotomy between the perceptions of patients and physicians regarding the impact of EHR systems on patient-physician relationship. ${ }^{1}$

2. In this study, physician perceptions of EHR interference were found to be significantly associated with which of the following attributes?
a. Physician age.
b. Amount of EHR training.
c. Physician specialty.
d. None of the above.

Correct Answer: The correct answer is option d. Several previous studies have found an association between physician perceptions of EHRs and their level of computer experience (Emani et al, ${ }^{18}$ Grinspan et $\mathrm{al}^{19}$ ) and specialty (Jamoom et al, ${ }^{22}$ Detmer and Friedman, ${ }^{23} \mathrm{O}^{\prime}$ Connell et al ${ }^{20}$ ). Our study, however, found no significant correlation with any of these attributes. Our results corroborate the findings of Rathert et $\mathrm{al}^{21}$ who found no major differences in physician perceptions of EHR interference based on age, gender, profession, or organization, and O'Connell el al, ${ }^{20}$ who found no significant correlation between physician age and EHR satisfaction.

\section{Protection of Human and Animal Subjects}

This study was approved by the medical ethics board of the medical faculty of the Pontificia Universidad Catolica. There was no risk for participants in the study, participant confidential information was stored in an encrypted database, and all participant identifiers were removed during data analysis.

Funding

None.

\section{Conflict of Interest}

None declared.

\section{References}

1 Gadd CS, Penrod LE. Dichotomy between physicians' and patients' attitudes regarding EMR use during outpatient encounters. Proceedings of the AMIA Symposium; 2000:275-279

2 Fairley CK, Vodstrcil LA, Huffam S, et al. Evaluation of Electronic Medical Record (EMR) at large urban primary care sexual health centre. PLoS One 2013;8(04):e60636

3 Schoen C, Osborn R, Squires D, et al. A survey of primary care doctors in ten countries shows progress in use of health information technology, less in other areas. Health Aff (Millwood) 2012; 31(12):2805-2816

4 World Health Organization. Chile: eHealth Country Profile. Published 2015. Available at: http://www.who.int/goe/publications/ atlas/2015/chl.pdf?ua=1\&ua=1. Accessed August 28, 2018

5 El-Kareh R, Gandhi TK, Poon EG, et al. Trends in primary care clinician perceptions of a new electronic health record. JGen Intern Med 2009;24(04):464-468

6 Sobral D, Rosenbaum M, Figueiredo-Braga M. Computer use in primary care and patient-physician communication. Patient Educ Couns 2015;98:1568-1576

7 Marmor RA, Clay B, Millen M, Savides TJ, Longhurst CA. The impact of physician EHR usage on patient satisfaction. Appl Clin Inform 2018;9(01):11-14

8 Alkureishi MA, Lee WW, Lyons M, et al. Impact of electronic medical record use on the patient-doctor relationship and communication: a systematic review. JGen Intern Med 2016;31(05):548-560

9 Zurita L, Nøhr C. Patient opinion-EHR assessment from the users perspective. Stud Health Technol Inform 2004;107(Pt 2):1333-1336

10 Rosen P, Spalding SJ, Hannon MJ, Boudreau RM, Kwoh CK. Parent satisfaction with the electronic medical record in an academic pediatric rheumatology practice. J Med Internet Res 2011;13(02):e40 
11 Lelievre S, Schultz K. Does computer use in patient-physician encounters influence patient satisfaction? Can Fam Physician 2010;56(01):e6-e12

12 Rethans J-J, Höppener P, Wolfs G, Diederiks J. Do personal computers make doctors less personal? Br Med J (Clin Res Ed) 1988;296 (6634):1446-1448

13 Garrison GM, Bernard ME, Rasmussen NH. 21st-century health care: the effect of computer use by physicians on patient satisfaction at a family medicine clinic. Fam Med 2002;34(05):362-368

14 Buscató CR, Yuste NE, Toirán AS, Díaz SB, Font J. Opinión de profesionales y pacientes sobre la introducción de la informática en la consulta [Views of professionals and patients on the introduction of computer science into the consultation]. Aten Primaria 2005;36:194-197

15 Cork RD, Detmer WM, Friedman CP. Development and initial validation of an instrument to measure physicians' use of, knowledge about, and attitudes toward computers. J Am Med Inform Assoc 1998;5(02):164-176

16 Lin TC. A computer literacy scale for newly enrolled nursing college students: development and validation. J Nurs Res 2011; 19(04):305-317

17 The Drummond Group. ONC HIT Certification Program: Test Results Summary for 2014 Edition EHR Certification. Available at: https://drummondgroup.com/wp-content/uploads/2018/07/
Test-Results-Summary-AlertEHR-v2.6.4-CompAmb-3Dec14.pdf. Accessed March 6, 2019

18 Emani S, Ting DY, Healey M, et al. Physician beliefs about the impact of meaningful use of the EHR: a cross-sectional study. Appl Clin Inform 2014;5(03):789-801

19 Grinspan ZM, Banerjee S, Kaushal R, Kern LM. Physician specialty and variations in adoption of electronic health records. Appl Clin Inform 2013;4(02):225-240

20 O'Connell RT, Cho C, Shah N, Brown K, Shiffman RN. Take note(s): differential EHR satisfaction with two implementations under one roof. J Am Med Inform Assoc 2004;11(01):43-49

21 Rathert C, Porter TH, Mittler JN, Fleig-Palmer M. Seven years after Meaningful Use: physicians' and nurses' experiences with electronic health records. Health Care Manage Rev 2019;44(01):30-40

22 Jamoom EW, Heisey-Grove D, Yang N, Scanlon P. Physician opinions about EHR use by EHR experience and by whether the practice had optimized its EHR use. JHealth Med Inform 2016;7 (04):1000240

23 Detmer WM, Friedman CP. Academic physicians' assessment of the effects of computers on health care. Proc Annu Symp Comput Appl Med Care 1994:558-562

24 Electronic Medical Records in Latin America and the Caribbean. An Analysis of the Current Situation and Recommendations for the Region. Washington, DC: PAHO; 2016 